\title{
CÍRCULOS MIMÉTICOS NO CONTO GREEN, DE SEFI ATTA ${ }^{1}$
}

DOI: $10.48075 /$ ri.v24i1.26219

Letícia Ritter de Abreu Valença²

Dionei Mathias ${ }^{3}$

RESUMO: Em sua obra literária, Sefi Atta ficcionaliza fluxos migratórios e experiências de globalização. Dentre as narrativas que compõem esta obra, o leitor encontra Green, um conto narrado do ponto de vista de uma criança e que é foco de discussão deste artigo. Ele retrata o momento em que os pais nigerianos da protagonista obtêm a documentação necessária para legalizar sua permanência nos Estados Unidos. A protagonista compartilha seu ponto de vista como representante da segunda geração de imigrantes, envolvendo o leitor nas experiências de seus pais. Com base na teoria da tripla mimese de Ricoeur (1994), entendida como círculos miméticos formados por processos de préfiguração, configuração e refiguração da composição ficcional, este artigo pretende discutir o processo de construção de sentido no conto Green, captando seu contexto de criação, discutindo sua ficcionalização e, por fim, buscando compreender as possibilidades de recepção (ECO, 2004). Em cada círculo mimético, o conto revela novos potenciais de sentido.

Palavras-chave: Sefi Atta, Green, Círculos miméticos.

\section{MIMETIC CIRCLES IN SEFI ATTA'S SHORT STORY GREEN ${ }^{4}$}

ABSTRAC: In her literary work, Sefi Atta fictionalizes migratory flows and experiences of globalization. Among the narratives that compose this oeuvre, the reader can find Green, a short story narrated from the point of view of a child, which is also the focus of this article. It portrays the moment in which the main character's Nigerian parents obtain the necessary documentation to legalize their stay in the United States. The protagonist shares her point of view as a representative of the second generation of immigrants, involving the reader in the experiences of her parents. Based on Ricoeur's theory of triple mimesis (1994), understood as mimetic circles formed by processes of pre-figuration,

${ }^{1}$ O presente trabalho foi realizado com apoio da Coordenação de Aperfeiçoamento de Pessoal de Nível Superior - Brasil (CAPES) - Código de Financiamento 001.

2 Mestranda no Programa de Pós-Graduação em Letras da UFSM. E-mail: leticiavalenca@gmail.com

${ }^{3}$ Doutor em Letras pela Universität Hamburg e pela UFPR. Professor do Departamento de Letras Estrangeiras Modernas e do Programa de Pós-Graduação em Letras da UFSM. E-mail: dioneimathias@gmail.com

${ }^{4}$ This study was financed in part by the Coordenação de Aperfeiçoamento de Pessoal de Nível Superior - Brasil (CAPES) - Finance Code 001. 
configuration and re-figuration of the fictional construction, this article aims to discuss the process of meaning making in the short story Green, capturing its context of creation, discussing its fictionalization and, finally, trying to understand the possibilities of reception (ECO, 2004 ). In each mimetic circle, the short story reveals new potentials for meaning.

Key Words: Sefi Atta, Green, mimetic circles.

\section{INTRODUÇÃO}

Considerada uma das principais escritoras de sua geração, Sefi Atta é uma autora nigeriana que escreve em inglês e cuja escrita vem se destacando internacionalmente. Nascida em 1964, educada na Nigéria, inicialmente, e, então, na Inglaterra e nos Estados Unidos, tem sua formação voltada para a área da contabilidade, antes que pudesse se dedicar à escrita criativa. Dentre outras formas de reconhecimento, seu trabalho recebeu prêmios literários como o Fish International Short Story Prize e o BBC Meridian Short Story Competition, em 2002, o Red Hen Press Story Award, em 2003 e o PEN International David TK Wong Prize, em 2005, dentre outros. Sua escrita cativante desperta reflexões afetivas e ideológicas, representando a complexa realidade do imigrante no atual contexto de globalização, com suas problemáticas de discriminação, bem como questões feministas.

De acordo com Nwokocha (2020, s. p.), Atta desenvolve personagens que atuam em espaços públicos, subvertendo as estruturas neo-coloniais, como a protagonista de seu romance de estréia, Everything Good Will Come (2004), que recusa cargos inferiores para se afirmar no contexto político. Em suas narrativas, figuras ficcionais ressignificam expectativas patriarcais culturalmente pré-estabelecidas e expõem fenômenos de transculturalidade. Em obras como Swallow (2010), The Bead Collector (2018) e Selected Plays (2018) temas como a maternidade, a passividade feminina e a restrição ao espaço doméstico são questionados, mas esses questionamentos também têm como foco regimes políticos opressivos e elites contraditórias. Ao manifestar autênticas experiências de mulheres - nigerianas ou não - que buscam a igualdade, a autora constrói realidades ficcionais em que o ativismo é posto em evidência e personalidades resistentes são promovidas.

Em sua coleção de contos, News From Home (2010), vencedor do Noma Award for Publishing in Africa, dentre outros prêmios, Atta multiplica vozes nigerianas que impactam por sua universalidade. A captação sensível da autora compreende aspectos da contemporaneidade, denunciando a violência institucionalizada, a injustiça e a hipocrisia de 
valores debruçados sobre interesses hegemônicos. Ao mesmo tempo, as histórias transnacionais, que viajam do continente africano ao americano, criticam de forma sutil problemáticas da imigração, da religião e da luta feminina. Assim, Atta reflete sobre questões importantes para o espaço cultural nigeriano, mas também volta sua atenção para centros hegemônicos, por onde transita, para pensar sobre a condição de imigrante. Nisso, ela se junta a um conjunto de vozes que discute os fluxos migratórios em contextos anglófonos (MATHIAS, 2018).

No conto Green, foco de análise deste artigo, ela apresenta um excerto dessa experiência de imigração com seus desafios de assimilação cultural, desenvolvendo uma perspectiva feminina e infantil. A partir dessa perspectiva, o leitor tem acesso a um mundo ficcional, em que se encena um dos momentos centrais no processo de oficialização, neste caso, da cidadania americana dos pais nigerianos. Ao longo da narrativa, o momento de obtenção do Green Card é intercalado com reflexões feitas pela protagonista acerca de sua origem, bem como de suas preocupações como criança americana. Nesse microcosmo do departamento de regulamentação de permanência, surge um espaço de confluência dos mais diversos fluxos migratórios.

Em seu estudo, Sara Schotland traça um panorama acerca da literatura de imigrantes, questionando o mito da fácil assimilação cultural e a comum tendência a ridicularizar a mobilidade social, dentro do contexto americano. Nisso, ela destaca o papel da literatura de fluxos migratórios, afirmando que esta tem o poder de refletir a experiência vivida por imigrantes em momentos de atrito intercultural, como dificuldades assimilativas como a internalização de um novo idioma, além da violência doméstica consequente da dominação patriarcal. De acordo com a estudiosa, o reflexo desse tipo de experiência na ficção oferece

\footnotetext{
uma experiência vicária para ajudar o leitor a viver a vida de outra pessoa, que pode pertencer a uma etnia, nacionalidade, classe social, gênero, idade ou condição corporal diferente. Narrativas de "outsider" trazem à atenção de leitores da classe média o efeito de políticas que impedem as aspirações emocionais ou econômicas de minorias e "Outros". Imigrantes, por definição, são os "outsiders" definitivos. Freqüentemente, imigrantes são "outsiders" em interseções múltiplas - eles podem ser não-brancos, pobres, gays ou transgêneros. A ficção nos convida a compreender e até mesmo abraçar indivíduos que são diferentes de nós, e incluí-los em nossas vidas sociais e políticas (SCHOTLAND, 2019, p. 88). ${ }^{5}$
}

\footnotetext{
5 "a vicarious experience to help the reader live the life of someone else, who may belong to a different ethnicity, nationality, social class, gender, age, or body status. "Outsider" narratives bring to the attention of middle class readers the effect of policies that hinder the emotional or economic aspirations of minorities and "Others." 
Ademais, ainda argumentando sobre narrativas que trazem a temática da experiência migratória para a ficção, Schotland (2019, p. 90) define tendências do gênero e, nesse estudo, as que são especialmente relacionáveis a construções como o conto Green remetem a experiências de hibridez e conflitos identitários. Nessa esteira, o trabalho de Walkowitz (2006, p.530) defende que a circulação multilíngue da literatura de imigrantes desestabiliza conceitos da cultura literária baseados em valores do estado-nação, ponto este reforçado através de criações ficcionais como as de Atta.

A partir dessa interseção entre realidade social e sua figuração ficcional, é interessante considerar a teoria de Paul Ricoeur (1994) acerca da tríplice mimese. Em seu estudo, o teórico francês entrelaça a noção de tempo com o movimento de representação mimética. Para ele, uma das formas de compreender a noção de tempo ocorre pelas articulações verbais. A fim de compreender a configuração da temporalidade através da narrativa, o autor destaca três círculos miméticos que abarcam o efeito da arte na sociedade e vice-versa. Esse círculo, porém, não representa um movimento vicioso, pois o tempo é configurado na narrativa através da linguagem e refigurado por meio do leitor, após sua decodificação.

Na mímesis I, que trata-se da prefiguração do campo prático, a ação apenas pode ser narrada porque ela "já está articulada em signos, regras, normas: é, desde sempre, simbolicamente mediatizada" (1994, p. 91). Para Ricoeur, os sentidos de imitação e representação são bastante próximos e significam pré-compreender semântica e hermeneuticamente o agir humano dentro da temporalidade. Partindo de tal précompreensão, compartilhada entre o produtor e o receptor da obra como seres sociais, a tessitura da intriga se desvela como um movimento de reconhecimento desse mundo présimbolizado. A mediação recupera conhecimentos desse primeiro círculo mimético, permitindo ao leitor criar conexões no processo de decodificação.

Embora estejamos falando de imitações da vida real, o leitor precisa de aptidão para compreender simbólica, temporal e estruturalmente a mediação. A mímesis II, que institui a linearidade da produção literária, é o enredamento ou agenciamento dos fatos. Mediando a percepção do agir humano (Mímesis I) e a refiguração pela recepção (Mímesis III), ela é posicionada entre o tempo e a narrativa. O mundo construído, entendido por Ricoeur como

Immigrants by definition are the ultimate outsiders. Often immigrants are outsiders through multiple intersections - they may be nonwhite, poor, gay or transgender. Fiction invites us to understand and even embrace individuals who are different from ourselves, and include them in our social and political lives" (SCHOTLAND, 2019, p. 88). 
livre das limitações que "o paradigma da tragédia impõe ao conceito da tessitura da intriga em Aristóteles" (1994, p. 102), é definido como tendo um maior grau de abstração, pensado sempre sob a lente da temporalidade. Aqui, é preciso considerar a esquematização artística, ou seja, a configuração que ficcionaliza a existência humana.

A obra, ao ser configurada por seu autor, ressignifica a experiência temporal, mas esse fato só é possível porque o leitor realiza a leitura, internalizando as referências e entendendo a forma de elaboração da narrativa. De acordo com Ricoeur, devemos às obras de ficção a "ampliação de nosso horizonte de existência" (1994, p. 123). A refiguração da obra pela recepção, portanto, pode fazer com que o leitor mude o seu agir, pois a compreensão de mundo pode ser modificada a partir da leitura. Sendo a interseção entre o mundo do texto e o do leitor, a mímesis III representa a detecção de valores realizada pela recepção. Esta, por sua vez, é transformada por esse processo, fato que reverbera na interação social. Concepções fixas e homogêneas, nesse estágio da captação literária, podem ser desestabilizadas, consolidando o convite ao exercício da empatia, com o objetivo de transformar a forma como o leitor reage socialmente.

Assim, eventos vividos são acrescidos a histórias narradas e assimiladas pelo leitor, que, por sua vez, volta a inserir os valores absorvidos e ressignificados no contexto social. Com base nos três círculos miméticos de Ricoeur (1994), este artigo deseja discutir o conto Green, de Sefi Atta, e verificar como as três esferas de representação dialogam. Para tanto, a partir do contexto social de sua produção, as noções de ambivalência (BAUMAN, 1999) e de hibridismo (CANCLINI, 1995) podem auxiliar na análise da configuração da intriga. Por fim, para exercitar o entendimento sobre a atualização de sentidos realizada pelo destinatário da obra, o conceito de Eco (2004) será utilizado como base, já que permite-nos aprofundar a reflexão a respeito da função do leitor na consolidação da unicidade da obra literária. Dessa forma, é possível compreender a contribuição recíproca entre a literatura e a realidade extradiegética, especialmente no que tange a questões ideológicas resultantes de problemas sociais que compõem a vida e a arte.

ELEMENTOS DA PRÉ-FIGURAÇÃO: SEDIMENTOS DO ESPAÇO SOCIOCULTURAL EXTRAFICCIONAL

Para que o momento sociocultural de pré-figuração da obra seja compreendido, é necessário considerar, em primeiro lugar, que sua produção ocorre dentro do que é 
considerado como tempo moderno. Portanto, é pertinente destacar o que observa Marshall Berman, no capítulo introdutório de Tudo o que é sólido desmancha no ar, sobre a formação do indivíduo que vive esse período. Para o autor, a "experiência ambiental da modernidade anula todas as fronteiras geográficas e raciais, de classe e nacionalidade, de religião e ideologia: nesse sentido, pode-se dizer que a modernidade une a espécie humana" (BERMAN, 2007, p. 24). Não se trata, porém, de uma unidade simples, pois é criada por uma "permanente desintegração e mudança, de luta e contradição, de ambiguidade e angústia". Ainda segundo o estudioso, embora a globalização tenha aproximado conexões interculturais, atualizando, assim, concepções tradicionais acerca da nação, da religião e de ideologias, diferenciações raciais e de classe têm sido cada vez mais detectáveis. A sensação de angústia pode ser confirmada, diante da intensificação com que conceitos historicamente definidos são desestabilizados.

Para Bauman (1999), o desconforto resultante da ideia de desordem advinda de tais desestabilizações de padrões pré-estabelecidos revela o problema da imposição de uma ordem com sentido sólido. É preciso aproveitar mudanças para exercitar a capacidade de tolerar o que emerge como ambíguo, já que isso leva a refletir sobre a formação de identidades, especialmente em momentos de crise. A permanente desintegração observada por Berman, gerada pela onda global de contradições, de fato destaca o advento da ambiguidade, experimentada pelas novas gerações. Estas, muitas vezes fruto de movimentos migratórios, vêm para questionar aquilo que, até então, era discursivamente construído como regra, pelas gerações anteriores. É possível compreender, então, que o contraste entre ordem e caos fragiliza o sentido. A diferenciação é empreendida por quem tem o poder discursivo de definir e, na contemporaneidade, há muitos atores sociais que questionam essas concepções - dentre elas, físicas, sexuais e nacionais - desestabilizando a ordem da diferenciação e instaurando tessituras de indeterminação.

O outro, como representante da diferença, é um causador central de desconforto e, ao entendermos que a "intolerância é, portanto, a inclinação natural da prática moderna" (BAUMAN, 1999, p. 16), podemos entender a tendência a deslegitimar e estereotipar o que difere da norma. Green, de Sefi Atta, produzido de forma a destacar os sutis matizes formadores das novas gerações, apresenta um espaço de múltiplos contatos culturais e é narrado por uma protagonista que, embora muito nova, é capaz de reconhecer e apreciar sua 
origem dupla. A partir de manifestações da autora, é possível identificar a natureza da percepção de mundo que dá origem a tal construção ficcional.

É notável a preocupação de Atta com a representatividade da produção cultural nigeriana, que não deve seguir apenas o que a mídia/ indústria editorial espera de autoras africanas (AZUAH; ATTA; UNIGWE, 2008, p. 109-110). Subvertendo a expectativa de construções ficcionais que alimentam estritamente a esperada luta da mulher negra contra o patriarcado, em Green, Atta opta por desenvolver uma realidade ficcional particular, sem deixar de oferecer resistência. Ideando uma cosmovisão que naturaliza o hibridismo cultural, a protagonista do conto apresenta uma focalização acostumada com a peculiaridade de suas raízes dentro da conhecida tentativa de socialização juvenil. De certa forma, a autora consegue romper a tendência da construção de um protagonista no papel de vítima, preferindo retratar nigerianos em sua existência cotidiana (AZUAH; ATTA; UNIGWE, 2008, p. 110), destacando um hábito de pessoas que optaram por cruzar nações em busca de oportunidades para uma construção familiar digna.

\section{ASPECTOS DA FIGURAÇÃO: A TRANSFORMAÇÃO DIEGÉTICA DA REALIDADE}

Muito sutilmente, a narrativa transforma um processo tipicamente monótono e burocrático em uma pletora de interconexões culturais. Em outras palavras, o agenciamento dos fatos que compõe a narrativa é realizado de forma a disponibilizar ao leitor uma oportunidade de identificar diversas formas de contato intercultural. A peculiaridade dessa narrativa reside no fato de que não se trata de um processo rotineiro de indivíduos participantes de culturas hegemônicas, ou seja, que não conhecem a necessidade de abandonar seu país em busca de estrutura política e/ou financeira. Diferentemente disso, trata-se de um processo mais conhecido por aqueles que se submetem ao longo e angustiante processo de tornar-se legal em uma nova nação.

A seriedade do momento final da conquista do Green Card pode ser captado graças ao que se pode reunir entre a focalização da jovem protagonista e, especialmente, pelo que ela consegue absorver das reações de seus pais. É possível compreender esse elemento da estruturação formal do conto em uma macroperspectiva, pelo viés inocente que transmite um evento formal e importante e, em uma microperspectiva, a assimilação que ela faz entre sua origem, sua nacionalidade e outras referências culturais perceptíveis. Nessa interseção de 
percepção, concretiza-se a hibridez que caracteriza a protagonista. Para melhor compreender indivíduos formadores de culturas híbridas, é pertinente destacar a definição desenvolvida por Canclini (1995) a respeito do hibridismo. De acordo com o autor, trata-se de "processos socioculturais em que estruturas ou práticas distintas, previamente existentes de forma separada, são combinadas para gerar novas estruturas, objetos e práticas" (1995, p. XXV) ${ }^{6}$. Embora a protagonista não problematize a hibridez como condição, sua constituição como personagem aponta para esse pertencimento duplo a que Canclini chama atenção.

Num primeiro momento, essa hibridez não chega a se destacar. No início do conto, a protagonista anuncia que esse momento será bastante tedioso. Com seus nove anos e diferentemente de pessoas que, desde seus primeiros anos, conhecem a intensa fragilização inerente a fluxos migratórios, a protagonista parece ter uma estrutura socioeconômica sólida, por seu acesso a livros, carro e televisão paga. No lugar de preocupação ou tensão, a atmosfera afetiva sugere que seus pais não terão problemas em obter seus Green Cards, podendo voltar ao Mississipi a tempo de assistir à partida de futebol. Esses detalhes mostram uma percepção do espaço que não instaura angústia, permitindo, ao invés disso, o tédio. Ao contrário de muitas outras famílias inseridas em fluxos migratórios, o contexto socioeconômico da protagonista permite uma experiência mais tranquila diante do ritual de passagem, em que consiste a obtenção do green card.

Esse mesmo espaço de percepção também fornece outros elos entre pré-figuração e sua configuração ficcional, começando a voltar o olhar para presença de elementos híbridos no espaço. Assim, a protagonista identifica a variedade linguística presente no local, mesmo que ela não compreenda a razão de tal fato:

O que eu não entendo é por que eles devem explicar as regras em diferentes idiomas aqui?

Não fumar é No fumar.

Proibido beber é Khong Duoc Uong.

Proibido comer é No Comer e Khong Duoc An

(ATTA, 2004 s.d.) $)^{7}$

Depois de lembrar das aulas de espanhol que tem na escola com Mr. Gonzalez, a protagonista faz conexões que possibilitam a exposição de outra evidência da formação

\footnotetext{
6 "sociocultural processes in which discrete structures or practices, previously existing in separate form, are combined to generate new structures, objects and practices" (1995, p. XXV).

7 "What I don't understand is why must they explain the rules in different languages here?

No Smoking is No Fumar.

No Drinking is Khong Duoc Uong.

No Eating is No Comer and Khong Duoc An" (ATTA, 2004 s.d.).
} 
híbrida da comunidade em que faz parte. Nesse quesito, é constatado um conflito de princípios religiosos, comum em nações que abrigam mais de uma origem cultural:

\begin{abstract}
Há pessoas aqui que se parecem com o Sr. Gonzalez. Pessoas de aparência indiana também, como minha amiga Areeba, que deixou nossa escola porque a religião católica a estava confundindo. Há pessoas que parecem chinesas para mim, mas sempre que digo isso, mamãe diz: nem todas são chinesas! Às vezes ela me dá nos nervos. Eu sou apenas uma criança. Há uma família que parece africana como nós, mas mamãe diz que eles devem ser haitianos porque um homem ao lado deles segue falando francês com seu filho (ATTA, 2004, s.d.) $)^{8}$.
\end{abstract}

Além disso, há uma intrigante ponderação acerca do estereótipo que envolve a população asiática e uma possível confusão de nacionalidades pela similaridade das aparências físicas, que pode ser resolvida pela diferença dos idiomas falados. Diante dos excertos expostos, há a representação de, pelo menos, quatro idiomas, o espanhol, inglês, francês e vietnamita, duas religiões, dentre elas a católica e a dármica (da amiga Areeba, que pode seguir o hinduísmo, o budismo, o jainismo ou o sikhismo, dentre outras) e de quatro origens, como a haitiana, africana, chinesa e indiana.

Outras variedades culturais integrantes do local em que a narrativa está ambientada podem ser percebidas a partir do momento em que seus pais recebem a liberação de seus Green Cards. Já que estão em New Orleans, o pai da família, enquanto dança Limbo, que é uma dança oriunda de Trinidad e Tobago, sugere aproveitar o desfile de Mardi Gras, proveniente da cultura Francesa, para celebrar sua permanência legal nos Estados Unidos. Embora a protagonista não esteja disposta a permanecer na cidade, pois tem pressa para voltar ao Mississipi, é possível conhecer uma experiência prévia da família através de um flashback. Nessa lembrança, elementos como a Deusa Oxum e a comida beignet, originárias, respectivamente, da cultura africana (especialmente, de países como a Nigéria e Benin) e francesa, além de uma diferenciação entre as culinárias chinesa e tailandesa, podem ser percebidas:

No ano passado, viemos para o Mardi Gras em Nova Orleans. O tempo estava ensolarado. Assistimos ao Desfile de Oxum na Canal Street. Eu estava tentando pegar as miçangas que as pessoas estavam jogando dos carros alegóricos. Eu preferia as douradas. Meu pescoço estava pesado. Mamãe não parava de gritar no meu ouvido:

\footnotetext{
8 "There are people here who look like Mr. Gonzalez. Indian looking people too, like my friend Areeba who left our school because Catholic religion was confusing her. There are people who look Chinese to me, but whenever I say this, Mom says, They're not all Chinese! Sometimes she gets on my last nerve. I'm just a kid. There is one family who looks African like us, but Mom says they must be Haitian because a man next to them keeps speaking French to their son" (ATTA, 2004, s.d.).
} 


\begin{abstract}
"Oxum é africano. As pessoas aqui não sabem. Ela é a deusa iorubá do amor." Seu hálito cheirava aos beignets que comemos no café da manhã. Papai estava dizendo: "Não estende a mão assim. É por isso que você não consegue pegar. Veja, há uma técnica para pegar as miçangas." "Que técnica?" Mamãe perguntou e papai deu um passo para frente para nos mostrar e um enorme confete preto bateu em seu rosto. Então tivemos que almoçar. Eu disse que queria comida chinesa. Eles disseram que queriam comida tailandesa. Mamãe disse que era tudo igual. "Chinês não é tailandês!", eu disse, e minha mãe perguntou: "Como você sabe a diferença quando se trata de comida?" Comemos King Cake no caminho de volta para o Mississippi (ATTA, 2004, s.d.) ${ }^{9}$.
\end{abstract}

Ao final do relato, eles comem King Cake, que, derivado da Europa, tradicionalmente carrega muitas cores, que podem representar justiça, fé e poder. Esse elemento também representa a festa cristã da epifania. Todos esses elementos culturais são mencionados, ou até dispostos, dentro do espaço geográfico americano. Não por acaso, o conto Green, cujo nome é uma cor que representa não apenas o Green Card, é composto por elementos de diversas outras cores, assim como o país que abriga a família em foco e é feito de muitas outras famílias multicores, com isso configurando na esfera diegética o elemento pré-figurado da diversidade.

No que concerne à variedade de cores presentes na obra, vale destacar as reflexões feitas pela protagonista acerca da cor verde, que ela associa com vegetais, com o campo de futebol e com a inveja entre mulheres. A cor também é mencionada para lembrar da documentação e da bandeira do país de origem de seus pais "Verde está para os passaportes dos meus pais. Verde branco verde é a cor da bandeira de seu país na África, Nigéria" (ATTA, 2004 , s.d. $)^{10}$. Ao final do processo de rememoração em volta do evento de Mardi Gras, a cor verde é utilizada para apanhar os elementos multiculturais presentes na memória dessa comemoração, como os confetes jogados na celebração, os granulados do King Cake e das cebolas do prato Pad Thai. Seguindo a ideia da mistura, ela observa: "Verde está para confusão" (ATTA, 2004, s.d.) $)^{11}$.

\footnotetext{
9 "Last year we came for Mardi Gras in New Orleans. The weather was sunny. We watched the Oshun Parade on Canal Street. I was trying to catch the beads people were throwing from the floats. I preferred the golds. My neck was weighed down. Mom kept yelling in my ear, "Oshun is African. People here don't know. She is the Yoruba goddess of love." Her breath smelled of the beignets we ate for breakfast. Dad was saying, "Don't just reach out like that. That's why you keep missing them. See, there is a technique to catching the beads." "What technique?" Mom asked and Dad stepped in front to show us and a huge black bead smacked him in the face. Then we had to eat lunch. I said I wanted Chinese. They said they wanted Thai. Mom said it was all the same. "Chinese is not Thai!" I said, and Mom asked, "How come you know the difference when it comes to food?" We ate King Cake on our way back to Mississippi" (ATTA, 2004, s.d.).

10 "Green is for my parents' passports. Green white green is the color of the flag of their country in Africa, Nigeria" (ATTA, 2004, s.d.).

11 "Green is for confusion" (ATTA, 2004, s.d.). 
A protagonista, que não se encaixa na origem usual americana, nem divide com os pais o mesmo nível de dificuldade de assimilação cultural, se comporta de forma a dissolver o sentido carregado pelos rótulos "americana" e "nigeriana". Diante do problema da imposição de ordem com sentido sólido, que condiciona o comportamento humano para incluir ou excluir indivíduos em ou de certos grupos sociais, a personagem em questão pode ser considerada ímpar por desestabilizar padrões. Seus pais se submetem ao imperativo da ordem, sem reconhecer a ambiguidade que permeia a existência da filha, como pode ser visto no momento em que a funcionária do órgão governamental emissor do Green Card os aborda sem saber que apenas os pais precisam da documentação: "Vamos tirar sua impressão digital hoje, querida? 'A linda mulher me pergunta. 'Não, ela é a americana da família,' mamãe diz e sorri" (ATTA, 2004, s.d.) ${ }^{12}$. A pergunta da funcionária a confronta explicitamente com a questão que envolve seu arraigamento cultural.

\section{DA CONFIGURAÇÃO À REFIGURAÇÃO EM PROCESSOS DE RECEPÇÃO}

As considerações acima resultam da captação das ideias não verbalizadas explicitamente. Cabe ao receptor da produção literária atualizar o sentido desta. O papel do leitor, ao refigurar o que foi construído na ficção, compreendendo a unicidade da obra, reside no entendimento de "trechos entremeados de espaços em branco, de interstícios a serem preenchidos" (ECO, 2004, p. 37). Afinal, o texto é um "mecanismo preguiçoso que vive da valorização de sentido que o destinatário ali introduziu" (ECO, 2004, p. 37). Assim, o destinatário da construção ficcional pode complementar e concluir o círculo mimético, contribuindo para a unicidade da obra ao adicionar a mensagem contida nesta a suas experiências prévias de leitura e cosmovisão pessoal. A obra, por sua vez, na medida em que soma vivências, valores e referências ao indivíduo leitor, é valorizada justamente por funcionar em prol da transformação e sensibilização da comunidade leitora.

Especificamente, uma obra como Green traz aos olhos do leitor uma percepção e um tipo de vivência únicos, que nem todas as pessoas precisam ou têm a oportunidade de vivenciar, embora tenha se fortalecido, no mundo globalizado. Esse conto também mostra novas dinâmicas no movimento de formação cultural, justamente diante dos processos

\footnotetext{
12 “Are we getting your thumb print today, Sweetie?' the pretty woman asks me. 'No, she's the American in the family,' Mom says and smiles" (ATTA, 2004, s.d.).

Ideação. Revista do Centro de Educação, Letras e Saúde. v. 24, n¹, 2022. e-ISSN: 1982-3010.
} 
contemporâneos que concretizam outras modalidades de realização pessoal e familiar. É importante conceber a formação híbrida das novas gerações e reconhecer que as gerações anteriores também são resultantes de processos de mistura cultural e racial. A diferença está nos distintos processos sociais e econômicos que impulsionaram e seguem impulsionando os particulares níveis de miscigenação étnica. $O$ trabalho de refiguração por parte do leitor auxilia nesse processo de atualização e reorganização das visões de mundo.

Atualmente, o que tem surgido como fenômenos culturais pode ser definido como ambivalente, não precisando ser classificado de forma terminante e peremptória. A ausência de mecanismos de controle linguístico para rotular e hierarquizar pode ser compreendido como elemento positivo, afirmador da diversidade. O conto auxilia o leitor a identificar que a realidade é híbrida e que as formas de ser no mundo são marcadas por ambivalências e diversidades. O leitor recebe por meio da experiência literária a oportunidade de conhecer outras confluências históricas, podendo, com isso, transformar sua visão de mundo. Ao reverberar valores, em seu meio social, ele pode contribuir para disseminar comportamentos inclusivos, atentos para a diversidade e desejosos de acolher a diferença.

\section{CONSIDERAÇÕES FINAIS}

A protagonista de Green, como imigrante de segunda geração, representa, com sua origem nigeriana e nascimento nos Estados Unidos, a formação de uma nova estrutura, que podemos chamar de afro-americana, e que não é apenas africana, nem apenas americana, alargando o escopo semântico do termo afro-americano, com novas experiências. Até certo ponto, o conto conecta a ideia de hibridismo cultural à noção de desordem, propiciando a percepção de uma nova formação social ambivalente e inquietante por não ser dominada pela linguagem. Nesse sentido, Bauman (1999, p. 14) explica: “A luta pela ordem não é a luta de uma definição contra outra, de uma maneira de articular a realidade contra uma proposta concorrente. É a luta da determinação contra a ambigüidade, da precisão semântica contra a ambivalência, da transparência contra a obscuridade, da clareza contra a confusão".

Nessa esteira, é possível compreender o pêndulo dicotômico entre aquilo que o leitor está habituado a nomear linguisticamente e aquilo que escapa à sua capacidade articulatória. Ao se encontrar diante da possibilidade da não dominação, experimenta inquietação. É necessário conhecer as realidades políticas e econômicas de espaços geográficos diversos, 
para que se compreenda a sociedade como um todo e para que a inquietação originária dessas transformações seja atenuada. O conto de Atta contribui para esse processo ao dialogar com os elementos pré-figurados do espaço cultural americano, configurá-los esteticamente na realidade diegética de seu conto e convidar o leitor a refigurar esse conjunto de sentidos, a fim de fazê-los circular em seu espaço de ação. Desse modo, os movimentos miméticos engendram círculos dialógicos, com um potencial substancial de transformação. 


\section{REFERÊNCIAS}

ATTA, S. Green. StorySouth, vol. 11, 2004, sem paginação.

AZUAH, U., ATTA, E., \& UNIGWE, C. Of Phases and Faces: Unoma Azuah Engages Sefi Atta and Chika Unigwe. Research in African Literatures, vol. 39, nr. 2, 2008, p. 108-116.

BAUMAN, Z. Modernidade e Ambivalência. Tradução de Marcus Penchel. Rio de Janeiro: Jorge Zahar, 1999.

BERMAN, M.: Tudo o que é sólido desmancha no ar. Tradução de Carlos Felipe Moisés e Ana Maria L. Ioriatti. São Paulo: Companhia das Letras, 2007.

CANCLINI, G. N. Hybrid Cultures: strategies for entering and leaving modernity. Tradução de Christopher L. Chiappari and Silvia L. López. Minneapolis: University of Minnesota Press, 1995.

ECO, U. Lector in Fabula. Tradução de Attílio Cancian. São Paulo: Perspectiva, 2004.

NWOKOCHA, S. "Sefi Atta". The Literary Encyclopedia. Disponível em: https://www.litencyc.com/php/speople.php?rec=true\&UID=12277. Acesso em 25 de outubro de 2020.

MATHIAS, D. Literatura e fluxos migratórios em contextos anglófonos: sobre a gênese discursiva de um campo de pesquisa. Scripta Uniandrade, v. 16, p. 225-238, 2018.

SCHOTLAND, S. Listen to the Voices: Immigrant Fiction Re-Considered. Humanities Bulletin, vol. 2, nr. 2, 2019, p. 87-101.

RICOEUR, P. Tempo e Narrativa (Tomo 1). Tradução de Constança Marcondes Cesar. Campinas: Papirus, 1994.

WALKOWITZ, R. Immigrant Fictions: Contemporary Literature in the Age of Globalization. Madison: University of Wisconsin System, 2006.

Recebido em 03 de novembro de 2020.

Aprovado em 08 de janeiro de 2021.

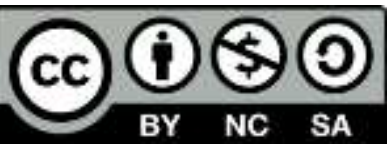

